\title{
Sensory evaluation, antioxidant activity and total of microbial of tamarind- turmeric herbal drink during the storage of refrigerator temperature at various packaging
}

\author{
*Septiana, A.T., Sitoresmi, I. and Dewi, P.S. \\ Faculty of Agriculture, Jenderal Soedirman University, Indonesia
}

\section{Article history: \\ Received: 6 February 2018 Received in revised form: 4 April 2018 \\ Accepted: 20 April 2018 \\ Available Online: 9 May 2018}

\section{Keywords: \\ Tamarind-turmeric herbal drink, \\ Types of packaging, \\ Storage refrigerator temperature}

\section{DOI:}

https://doi.org/10.26656/fr.2017.2(4).030

\begin{abstract}
Tamarind-turmeric herbal drink was vulnerable to microbes which may affect the sensory and antioxidant properties. Since so, it needs to be stored in a proper package at refrigerator temperature. The purpose of this research was to determine the effect of packaging and shelf life of the total of microbial, sensory and antioxidant of tamarindturmeric herbal drink during the storage of refrigerator temperature. The types of packaging used were polyethylene plastic bags, polypropylene plastic cups, and brown glass bottles. The duration of storage for microbial test ware 2, 4, 10, and 14 days, while for the sensory test, total phenol and DPPH free radical scavenging were 2 and 10 days. Results indicated that the storage of tamarind-turmeric herbal drink in a proper package at refrigerator temperature up to 10 days was still appropriate for consumption since the total of microbes are $<10^{6} \mathrm{CFU} / \mathrm{mL}$ which is acceptable based on the sensory property. Tamarind-turmeric herbal drink stored for two days had similar total phenolic content and DPPH free radical scavenging, but it was more yellow, lower bitter taste and preferred than the herbal drink stored for ten days. The longest storage of tamarind-turmeric herbal drink at refrigerator temperature was ten days with the best packaging of brown glass bottles. It has the following specification: dark yellow colour (4), slightly bitter taste (3.63), rather likes (3.29), total phenol $0.71 \%$ and DPPH scavenging activity at $40000 \mathrm{ppm}$ is $84.39 \%$.
\end{abstract}

\section{Introduction}

A healthy lifestyle can be performed by consuming natural products that nourish the body, such as functional food products. Functional food is a food or beverage product containing active compounds that play a role in maintaining the health of the body, such as preventing diseases, increasing immunity, slowing the aging process, and it does not have side effects to the metabolism of other nutrients (Hasler, 2002). To provide health benefits, functional food must also be acceptable sensorially (Siro et al., 2008). One of the functional foods is a tamarind turmeric drink.

Tamarind turmeric drink is made from turmeric, tamarind and coconut sugar. In this research, tamarind turmeric drink is made by mixing with spices of cardamom, cloves, ginger and lemongrass. Tamarind, turmeric and the spices contain bioactive compounds that can act as antioxidants or antimicrobials, such as curcumin and the components of essential oils in turmeric (Chattopadhyay et al., 2014), phenolic compounds in tamarind (Sandesh et al., 2014) and in the other spices. The addition of the spices to traditional Indonesian beverages can increase the antioxidant activity of the drink (Septiana et al., 2017).

The content of bioactive compounds in tamarind turmeric drink is mainly curcumin that can serve as antioxidant and antimicrobial. Curcumin has highly reactive properties against alkaline $\mathrm{pH}$ and light (Kumavat et al., 2013) and is not heat resistant (Siddiqui, 2015). The packaging of tamarind turmeric drink commonly used by herbalist sellers is a polyethylene plastic bag that has high permeability to water vapor and is translucent so that it is assumed of not being able to sustain damage to the bioactive components of the product. Packaging should have the main functions, such as to protect the product from microbes, physical or chemical damages (Marsh and Bugusu, 2007), so the product can be accepted after long enough storage. Polypropylene plastic cup and brown glass bottles are often found on the market so that in this study conducted study storage of tamarind turmeric drink on polyethylene 
plastic bags, polypropylene plastic cup, and glass bottle brown.

Beverage product is easily damaged at room temperature. Temperature is one of the factors that affect the growth of microbes. Normal temperature for storage is the temperature that does not cause significant damage or the decrease in product quality. The damages resulted in the product not being able to survive for a long time so that it needs the appropriate packaging (Marsh and Bugusu, 2007) and storage at low temperatures.

The purposes of this research were to found out the effects of packaging variation and shelf life to total microbiology, sensorial and antioxidant of tamarind turmeric drink during the storage of refrigerator temperature $\left( \pm 4^{\circ} \mathrm{C}\right)$ and to found out the combination of packaging type and the longest shelf life of tamarind turmeric drink in storage at refrigerator temperature that produce the best characteristics. This research is expected to be used as an alternative packaging technology of tamarind turmeric drink with the longest shelf life which can maintain total microbiology, sensorial and antioxidant of tamarind turmeric drink during the storage of refrigerator temperature.

\section{Materials and methods}

\subsection{Materials and tools}

The materials used in making tamarind turmeric drink were turmeric, tamarind, lemongrass, cardamom, cloves, brown sugar, and water. The packaging used was polyethylene plastic (PE) with $0.01 \mathrm{~mm}$ thickness (Boyo), $0.07 \mathrm{~mm}$ plastic cup (Karya Jaya Abadi), and brown glass bottles.

The chemicals used were $\mathrm{NaCl}$ (Merck), PCA (Plate Count Agar), ethanol, Folin-Ciocalteau, $\mathrm{Na}_{2} \mathrm{CO}_{3}$, ionfree water, methanol, and DPPH (1.1-diphenyl-2picrylhydrazyl) and aquades. The tools used were gas stove (Niko), stainless steel pan, infrared thermometer (Krisbow), cup sealer (Nankai), blender (Philips), refrigerator (Panasonic), UV-Vis spectrophotometer (Shimadzu 1240), sterilization oven (Binder), furnace oven (Memmert), scale (Ohaus), measuring pipettes (Pyrex), laminar flow, incubator (Memmert), and refractometer (Krisbow).

\subsection{Making tamarind turmeric drink}

The manufacture of tamarind turmeric drink requires spices $(16 \%)$ in the form of turmeric, tamarind and extra spices (lemongrass, cardamom, and cloves). Other materials used are coconut sugar $(10 \%)$, and water. At first, turmeric, extra spices, and water are mixed and filtered using a filter cloth, thus obtaining turmeric extract. Turmeric extract mixed with tamarind, coconut sugar, and water while stirring at $90{ }^{\circ} \mathrm{C} 10$ minutes and filtered to get tamarind turmeric drink.

\subsection{Packaging and storage of tamarind turmeric drink}

Tamarind turmeric drink is packed in polyethylene plastic bag, polypropylene plastic cup, or brown glass bottle. Initially the packaging of polyethylene plastic and polypropylene plastic cup sterilized under UV lamp for 5 -10 minutes. The brown glass bottle is washed and dried using a $100^{\circ} \mathrm{C}$ oven to dry. The drink was subjected to refrigerator storage at $4^{\circ} \mathrm{C}$ for subsequent total microbiological analysis for two days, six days, ten days, and 14 days; sensory and antioxidant analysis for two days and ten days. The determination of the duration of storage of tamarind turmeric drink is based on sensory evaluation results during storage. Based on the sensory reception, the shelf-life of the tamarind turmeric drink at room temperature in open pack is 24 hours ( 2 days) and in polyethylene plastic bag packaging is 72 hours. Based on the sensory reception, the shelf-life of the tamarind turmeric drink at refrigerator temperature in open pack is 52 hours and in polyethylene plastic bag packaging is 210 hours (10 days).

\subsection{Microbiological analysis}

Microbiological analysis is performed by measuring the total number of microbes using the pour plate method (SGM, 2006).

\subsection{Determination of total phenolic content}

Total phenolic compound of tamarind turmeric herbal drink was determined by Folin-Ciocalteau methods (Andarwulan and Shetty, 1999). $1 \mathrm{~mL}$ sample was diluted with $1 \mathrm{~mL}$ of $95 \%$ ethanol and $5 \mathrm{~mL}$ ion-free water and was mixed with $0.5 \mathrm{~mL}$ of $50 \%$ FolinCiocalteau. After $5 \mathrm{~min}$ incubation, $1 \mathrm{~mL}$ of $5 \%$ sodium bicarbonate was added, and the mixture was mixed and allowed to stand at room temperature for $60 \mathrm{~min}$. Results were expressed as percent of total phenolic content or as milligram of tannic acid equivalent per $\mathrm{mL}$ sample.

\subsection{DPPH scavenging assay}

The DPPH free radical scavenging assay was carried out by following the procedure of Sheikh et al. (2009). 2 $\mathrm{mL}$ of tamarind turmeric herbal drink (1250-40000 ppm) was added by $2 \mathrm{~mL}$ of $0.15 \mathrm{mM}$ DPPH in methanol, and this mixture was incubated for $30 \mathrm{~min}$ in the dark. The absorbance was noted at $517 \mathrm{~nm}$. A decrease in absorbance of the reaction mixture showed a good free radical inhibition potential of drink. The solution without sample was used as control. 
DPPH Scavenging Activity (\%) $=\frac{\text { Abs.Control-Abs.Sample }}{\text { Abs.Control }} \times 100 \%$

The DPPH radical scavenging ability of each sample was expressed as the half maximal inhibitory concentration on DPPH free radicals (IC50).

\subsection{Sensory evaluation}

The sensory parameter was performed with a scaling method on color, flavor, bitter taste, sour taste, and overall acceptability value using 20 semi-trained panelists from the students of Food Science and Technology study program, Jenderal Soedirman University, Indonesia. This test using a five scale $(1=$ very low and $5=$ very high) for yellow, flavor, sour taste and overall acceptability, and $(1=$ very high and $5=$ very low) for the bitter taste, according to the method described by Poste et al. (1991).

\subsection{Statistical analysis}

The test results were analyzed by analysis of the variant (ANOVA) followed by Duncans multiple ranges (DMRT) for a total of microbial, total phenolic contents and DPPH scavenging activity and Turkeys test for sensory evaluation.

\section{Results and discussion}

\subsection{Total of microbial}

Figure 1 shows that the total of microbial of tamarind turmeric drink stored in polyethylene (PE) plastic bag and polypropylene (PP) plastic cup is higher than the total of microbial in a brown glass bottle. According to Marsh and Bugusu (2007), plastic packaging offers a large range of barrier properties but is more permeable than glass. The difference in the total number of microbes is assumed due to differences in permeability to water and water vapor on each pack. The higher water vapor and air that can penetrate into the packaging cause the microbes to grow more because water is one of the determinants of microbial growth.

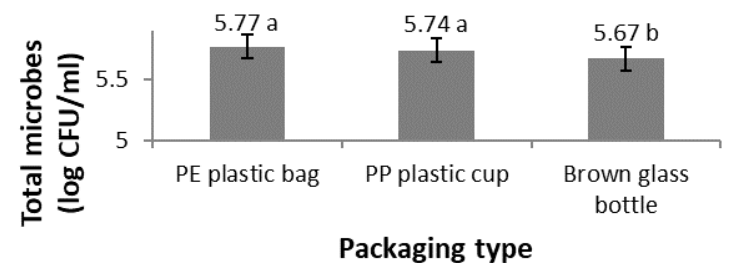

Figure 1. The effect of packaging type on a total of microbial of tamarind turmeric drink.

PE plastic bag and PP plastic cup have a higher permeability to oxygen and water vapor than glass bottle so that microbes are easy to grow in tamarind turmeric drink in the plastic packaging. Oxygen can also cause curcumin to oxidize, resulting in decomposition into smaller molecular weight compounds. Curcumin can act as antimicrobial, and the degradation of the compounds causes the antimicrobial activity to be reduced.

Figure 2 shows that the longer shelf life, the higher number of microbes in tamarind turmeric drink. A similar result occurs in the storage of raw milk at refrigerator temperature (Perko, 2011). Tamarind turmeric contains nutrients needed by microbes to grow so that longer shelf life provides sufficient time for microbes to grow. According to Kristianingrum (2009), every $100 \mathrm{~g}$ of coconut sugar contains $3 \mathrm{~g}$ of protein, 76 $\mathrm{g}$ of carbohydrates, $10 \mathrm{~g}$ of fat, $76 \mathrm{mg}$ of calcium, $37 \mathrm{mg}$ of phosphorus, and $3 \mathrm{mg}$ of iron.

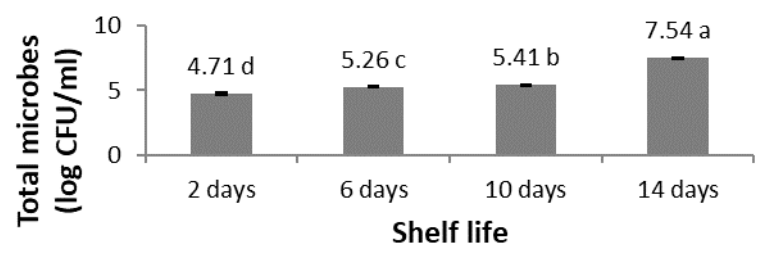

Figure 2. The effect of shelf life on a total of microbial of tamarind turmeric drink.

The microbial growth phase includes lag phase, exponential or log phase, stationary phase, and phase of death. In the lag phase, there is no increase in the number of microbes. However, in the exponential phase there is an increase in the number of microbes to the maximum number (Pelczar et al., 2010). The results showed that the number of microbes in storage from 2 to 14 days at refrigerator temperature has increased so that it is possible that the microbial growth phase has reached the exponential phase. It has been suspected that at the beginning of storage, the drink has already contained microbes since there was no sterilization before. The existence of such enabling conditions as nutrients in tamarind turmeric drink causes the number of microbes to increase. Increasing the number of microbes at the beginning of storage is 2 to 6 days lower than the increase in the number of microbial storage 10 to 14 days. Suspected of bioactive components that act as antimicrobials and antioxidants such as curcumin prevent growth in early storage.

Total of microbial of tamarind turmeric drink on various packaging during storage at refrigerator temperature for 2, 6, 10 and 14 days presented in Table 1. The shelf life of tamarind turmeric drinks up to 10 days still meet Indonesian National Standard (SNI) 192897-1992 (BSN, 1992) because the total of microbial of tamarind turmeric drink is less than $10^{6} \mathrm{CFU} / \mathrm{mL}$. Tamarind turmeric drink with 14 days shelf life is estimated to have passed the period of product worth consuming because of the total of existing microbes exceed the maximum limit of Indonesian National 
Table 1. Total of microbial in tamarind turmeric drink in various packaging during storage at refrigerator temperature for $2,6,10$ and 14 days.

\begin{tabular}{lcccc}
\hline \multirow{2}{*}{ Type of Packaging } & \multicolumn{3}{c}{ Total of microbial during storage $(\mathrm{CFU} / \mathrm{mL})$} \\
\cline { 2 - 5 } & 2 days & 6 days & 10 days & 14 days \\
\hline Polyethylene plastic bag & $6.3 \times 10^{4}$ & $2.05 \times 10^{5}$ & $2.77 \times 10^{5}$ & $3.67 \times 10^{7}$ \\
Polypropylene plastic cup & $5.7 \times 10^{4}$ & $1.84 \times 10^{5}$ & $2.64 \times 10^{5}$ & $3.50 \times 10^{7}$ \\
Brown glass bottle & $4.2 \times 10^{4}$ & $1.68 \times 10^{5}$ & $2.33 \times 10^{5}$ & $3.28 \times 10^{7}$ \\
\hline
\end{tabular}

Table 2. Sensory characteristic of tamarind turmeric drink in various packaging during storage at the refrigerator for two and ten days

\begin{tabular}{ccccccc}
\hline \multirow{2}{*}{ Packaging type } & \multirow{2}{*}{ Shelf life } & \multicolumn{3}{c}{ Sensory characteristic } \\
\cline { 3 - 7 } & & \multirow{2}{*}{ Color } & \multirow{2}{*}{ Flavor } & Sour taste & Bitter taste & $\begin{array}{c}\text { Overall } \\
\text { acceptability }\end{array}$ \\
\hline \multirow{2}{*}{ Polyethylene plastic bag } & 2 days & $3.78 \pm 0.25^{\mathrm{b}}$ & $3.83 \pm 0.28$ & $3.73 \pm 0.08$ & $3.98 \pm 0.34^{\mathrm{a}}$ & $3.52 \pm 0.43^{\mathrm{a}}$ \\
& 10 days & $3.48 \pm 0.40^{\mathrm{c}}$ & $3.82 \pm 0.21$ & $3.65 \pm 0.13$ & $3.50 \pm 0.36^{\mathrm{d}}$ & $3.07 \pm 0.34^{\mathrm{d}}$ \\
\multirow{2}{*}{ Polypropylene plastic cup } & 2 days & $4.40 \pm 0.23^{\mathrm{a}}$ & $3.73 \pm 0.20$ & $3.57 \pm 0.42$ & $3.87 \pm 0.53^{\mathrm{a}}$ & $3.53 \pm 0.43^{\mathrm{a}}$ \\
& 10 days & $3.82 \pm 0.45^{\mathrm{b}}$ & $3.92 \pm 0.18$ & $3.65 \pm 0.22$ & $3.65 \pm 0.23^{\mathrm{bc}}$ & $3.25 \pm 0.28^{\mathrm{bc}}$ \\
Brown glass bottle & 2 days & $4.43 \pm 0.21^{\mathrm{a}}$ & $3.68 \pm 0.19$ & $3.48 \pm 0.23$ & $3.77 \pm 0.28^{\mathrm{ab}}$ & $3.43 \pm 0.29^{\mathrm{ab}}$ \\
& 10 days & $4.00 \pm 0.30^{\mathrm{ab}}$ & $3.68 \pm 0.13$ & $3.62 \pm 0.36$ & $3.63 \pm 0.40^{\mathrm{bc}}$ & $3.23 \pm 0.38^{\mathrm{bc}}$ \\
\hline
\end{tabular}

Mean \pm SD ( $n=20)$. Means with different letters within the same column are significantly different from one another $(\mathrm{p}<0.05)$

Standard (SNI).

\subsection{Sensory evaluation}

Sensory characteristic of tamarind turmeric drink on various packaging during storage at the refrigerator for two and ten days which include color, flavor, sour taste, bitterness, and acceptability are presented in Table 2 . Tamarind turmeric drink shows colors ranging from brownish yellow to yellowish brown. The color of tamarind turmeric drink is affected by curcumin as yellow coloring agent from turmeric, sour taste from tamarind and brown color from coconut sugar. According to Kumavat et al. (2013), curcumin is yellow at $\mathrm{pH} \mathrm{1-7}$ and turns to red at $\mathrm{pH}>7.5$. The color of brownish in tamarind turmeric drink is also affected by the addition of brown sugar. Cookies with brown sugar are also brown color than cookies added with cane sugar (Nishibori and Kawakishi, 1992).

The storage of tamarind turmeric drink in polyethylene plastic bag for two days caused the color of tamarind turmeric drink to be browner than those that were stored in brown glass bottles and plastic cups. This condition is assumed because the oxidation of lipids in the drinks stored in a plastic bag is caused by higher oxygen and light exposure than in the brown glass bottles. The result of lipid oxidation causes the color of the drink to be darker.

The drinks stored for ten days have a browner color than those that were stored for two days. Storage of tamarind-turmeric drink at refrigerator temperature can cause discolorization. The same thing happens in the storage of sliced turmeric in the open place. The reduction of this fat content is assumed to be related to the occurrence of fat oxidation (Plotto, 2004).
PE plastic bag and PP plastic cup have a transparent appearance so that the light in the refrigerator can penetrate into the packaging. The effect of light from the refrigerator on the color of the drink based on curcumin damage is still unclear. Curcumin is a component in turmeric that affects the color of tamarind turmeric drink. Light can cause curcumin to decompose (Kumavat et al., 2013) causing the change of color from yellow to brownish yellow. The result of further research conducted by Kadam et al. (2013) indicates that visible light did not affect the color of turmeric powder, in contrast to the effect of ultraviolet (UV) light. The light in the refrigerator is usually a LED light which is visible light instead of UV so that based on the research, the light in the refrigerator does not affect the color.

Table 2 indicates that the storage of tamarind turmeric drink packaged in a plastic bag, plastic cup, and glass bottle increases bitter taste. The result of this research is consistent with the research conducted by Duraisankar and Ravindran (2015) which showed that the storages cause the increasingly bitter taste of turmeric. The bitter taste is assumed to be the interaction of the various existing components in the tamarind turmeric drink.

The overall acceptability of tamarind turmeric drink is assumed to be affected by color and bitter taste of the product. Tamarind turmeric drink with a brownishyellow color and a taste that is neither too sour nor too bitter is preferred. Tamarind turmeric drink on all three packages stored for two days is preferred than those stored for ten days because tamarind turmeric drink with stored for two days produces preferred color and bitter taste. Also, tamarind turmeric drink on the three packages stored for two and ten days has the amount of microbe contamination that is still below the Indonesian 


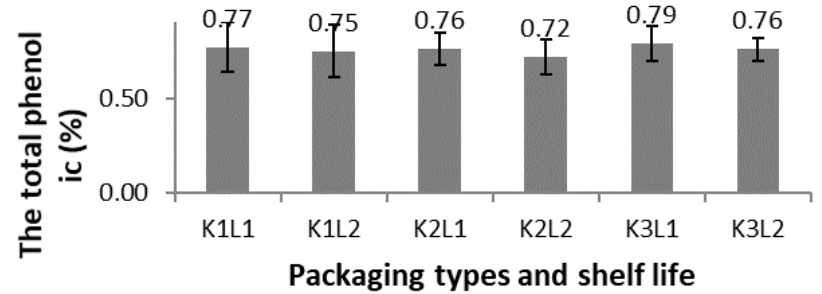

Figure 3. The total phenol content in tamarind turmeric drink in various packaging during the storage. $\mathrm{K} 1=\mathrm{PE}$ plastic bag, $\mathrm{PP}$ plastic cup, $\mathrm{K} 3=$ brown glass bottle; $\mathrm{L} 1=2$ days, $\mathrm{L} 2=10$ days

National Standard (SNI) or in other words; the tamarind turmeric drink is still worth consuming.

\subsection{Antioxidant activity}

The total phenolic content indicates the content of the phenolic substances in tamarind turmeric drink as phenolic antioxidants. According to Kikugawa et al. (1990), phenolic antioxidants are used to prevent or delay the autoxidation of fats and oils by free radicals scavenging activity.

Figure 3 shows that the storage of tamarind turmeric drink packaged in PE plastic bag, PP plastic cup and brown glass bottle at the refrigerator temperature tends to decrease the total phenolic content in the drink. During the storage, tamarind turmeric drink can occur lipid oxidation reaction resulting in the decrease of fat content to form free radicals that can attack the phenolic component. Curcumin is the most commonly found phenolic component in turmeric, which may also be most commonly found in tamarind turmeric drink. The oxidant reaction of curcumin can produce a condensation result which is presumably still in the form of the phenolic compound. The results of Gordon's study (2014) showed that curcumin can be autooxidation. Curcumin autoxidation is initiated by hydrogen abstraction from either of the two phenolic hydroxyls in the symmetrical molecule. After hydrogen abstraction, the ring bearing the phenoxyl radical and eventual quinone methide will determine the position of the incorporated oxygen atoms in the final product.

PE plastic bag and PP plastic cup have a transparent appearance so that the light in the refrigerator can penetrate into the packaging. The effect of light from the refrigerator on the damage to curcumin is still unclear. Similarly, its effect on the color of curcumin is also unclear because there is a possibility that the visible light is not ultraviolet light.

DPPH (1,1-diphenyl-2-picrylhydrazyl) is often used to test the antioxidant ability to donate hydrogen atoms. DPPH is one of a few stable and commercially available organic nitrogen radical and has a UV vis absorption

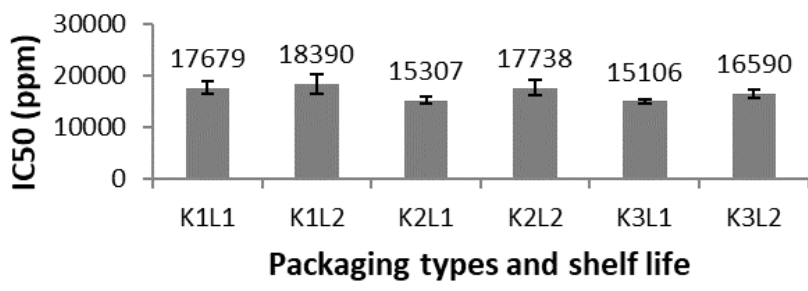

Figure 4. The value of $\mathrm{IC}_{50}$ of tamarind turmeric drink in various packaging. during storage. $\mathrm{K} 1=\mathrm{PE}$ plastic bag, $\mathrm{PP}$ plastic cup, K3= brown glass bottle; L1 $=2$ days, $\mathrm{L} 2=10$ days

maximum at $515 \mathrm{~nm}$. Upon reduction, the solution color fades. The color changing occurs when the radical electron of DPPH is paired with hydrogen from antioxidant to form DPPH-H (Huang et al., 2015).

The testing of DPPH scavenging activity by tamarind turmeric drink is conducted from concentration of $1250 \mathrm{ppm}$ to $40000 \mathrm{ppm}$. The research result indicates that the increasing concentration of the drink increases the free radicals capture capacity. At the drink concentration of $40000 \mathrm{ppm}$, the treatment of packaging type and shelf life do not affect the DPPH scavenging activity of the drink ranging from 81.57 to $85.67 \%$. This free radical scavenging activity is greater than free radical scavenging of turmeric instant drink extracted using only $78 \%$ of ethanol (Setyowati and Suryani, 2013). It is assumed that the difference of concentration and the addition of tamarind in tamarind turmeric drink affect DPPH radical scavenging activity.

Testing of DPPH scavenging activity is also tested by calculating $\mathrm{IC}_{50}$ which is the concentration of tamarind turmeric drink when the drink has free radical capture capacity of $50 \%$. The lower the value of $\mathrm{IC}_{50}$, the more effective the drink in capturing free radicals.

Figure 4 shows that the value of $\mathrm{IC}_{50}$ of tamarind turmeric drink stored for ten days $\left(\mathrm{IC}_{50}=16590-18390\right.$ ppm) tends to be greater than those stored for two days $\left(\mathrm{IC}_{50}=15106-17679 \mathrm{ppm}\right)$. The free radical capture capacity by tamarind turmeric drink stored for ten days at refrigerator temperature tends to be lower than those stored for two days. The storage of tamarind turmeric drink tends to reduce the ability of the drink in capturing DPPH radicals. Reduction of free radical capturing capacity by tamarind turmeric drink during storage is thought to be caused by the autooxidation of curcumin.

The antioxidant ability as DPPH scavenging activity is associated with the antioxidant ability to provide hydrogen protons. Various phenolic compounds can contribute to free radical capture capacity with different capacities. The research result indicates that free radical capture capacity of the drink stored for ten days tends to be smaller than those stored for two days. According to 
Agnihotri and Mishra (2011), curcumin can be degraded into ferulic acid and vanillin. The free radical capture capacity of curcumin is greater than ferulic acid and vanillin.

\section{Conclusion}

The packaging of tamarind turmeric drink commonly used by herbalist sellers is a polyethylene plastic bag. Polypropylene plastic cup and brown glass bottles are often found on the market so that in this study conducted study storage of tamarind turmeric drink on polyethylene plastic bags, polypropylene plastic cup, and glass bottle brown. The result of preliminary research indicated that the sensory property of tamarind-turmeric herbal drink after two days of refrigerator temperature storage in the open packaging had changed, while in the plastic bag packaging can be stored for ten days. The tamarind turmeric drinks packaged in brown glass bottle has a lower total of microbial and a more yellow color than the tamarind turmeric drink packaged in polyethylene plastic and polypropylene plastic cup. The increasing shelf life of tamarind turmeric drink from 2 days at refrigerator temperature to 14 days increases the total of microbial. The tamarind turmeric drink stored for ten days is still worth consuming because the total of microbial is less than $10^{6} \mathrm{CFU} / \mathrm{mL}$. The tamarind turmeric drinks stored for two days have a total phenol content, and free radical capture capacity which is not different but has a more yellow color, a lower bitter taste and is preferred than those stored for ten days. The longest shelf life of tamarind turmeric drink at refrigerator temperature is ten days with the best packaging in the form of brown glass bottles. The drink has a dark yellow color (4), slightly bitter taste-bitter (3.63), rather likes (3.29), total phenol $0.71 \%$ and DPPH scavenging activity at $40000 \mathrm{ppm}$ is $84.39 \%$.

\section{Conflict of Interest}

This article has no conflict of interest with any party or case.

\section{Acknowledgments}

This study was support by Ministry of Research, Technology and Higher Education Republic of Indonesia.

\section{References}

Agnihotri, N. and Mishra, P.C. (2011). Scavenging mechanism of curcumin toward the hydroxyl radical: a theoretical study of reactions producing ferulic acid and vanillin. The Journal of Physical Chemistry A, 115(49), 14221-14232. https://doi.org/10.1021/ jp209318f

Andarwulan, N. and Shetty, K. (1999). Phenolic content in differentiated tissue culture of transformed and Agrobacterium-transformed roots of anise (Pimpinella anisum L). Journal of Agricultural and Food Chemistry, 47, 1776-1780. https:// doi.org/10.1021/jf981214r

BSN. (1992). Cara Uji Cemaran Mikroba (SNI 01-2897). Retrieved on Oct 2017 from National Standardization Agency of Indonesia, Jakarta Website: www.sispk.bsn.go.id.

Chattopadhyay, I., Biswas, K., Bandyopadhyay, U. and Banerjee, R.K. (2004). Turmeric and curcumin: biological actions and medicinal applications. Current Science, 87(1), 44-53.

Duraisankar, R. and Ravindran, A.D. (2015). Identification of Curcuma longa rhizomes by physicochemical and TLC fingerprint analysis. International Journal of PharmTech Research, 8(6), 198-205.

Gordon, O. (2014). Oxidative Transformation of Curcumin: Products and Reaction Mechanisms. Nashville, Tennessee, USA: Vanderbilt University, PhD Dissertation.

Hasler, C.M. (2002). Functional foods: Benefits, concerns, and challenges-A position paper on science and health. The Journal of Nutrition, 132, 3772-3781. https://doi.org/10.1093/jn/132.12.3772

Huang, D., Ou, B. and Prior, R.L. (2005). The chemistry behind antioxidant capacity assays-Reviews. Journal of Agricultural and Food Chemistry, 53, 1841-1856. https://doi.org/10.1021/jf030723c

Kadam, P.V., Yadav, K.N., Patel, F.A., Karjikar, F.A., Patidar, M.K. and Patil, M.J. (2013). Pharmacognostic, phytochemical and physicochemical studies of Curcuma longa Linn rhizome. International Journal of Pharmacy, 3(3), 514-520.

Kikugawa, A., Kunugi, A. and Kurechi, T. (1990). Chemistry and implications of degradations of phenolic antioxidants. In Hudson, B.J.F. (Ed.) Food Antioxidant, p. 65-95. New York: Elsevier Applied Science. https://doi.org/10.1007/978-94-009-07539_3

Kristianingrum. (2009). Analysis Nutrition in Gula Semut. Yogyakarta, Indonesia: Universitas Negeri Yogyakarta.

Kumavat, S.D., Chaudhari, Y.S., Borole, P., Mishra, P., Shenghani, K. and Duvvuri, P. (2013). Degradation studies of curcumin. International Journal of Pharmacy Review and Research, 3, 50-55.

Marsh, K. and Bugusu, B. (2007). Food packaging- 
roles, materials, and environmental issues. Journal of Food Sciences, 72(3), 39-55. https:// doi.org/10.1111/j.1750-3841.2007.00301.x

Nishibori, S. and Kawakishi, S. (1992). Effect of various sugars on the quality of baked cookies. Cereal Chemistry, 69(2), 160-163.

Pelczar, M.J., Chan, E.C.S. and Krieg, N.R. (2010). Microbiology: An Application-Based Approach. New Delhi: Tata Mc Graw Hill.

Perko, B. (2011). Effect of prolonged storage on microbial quality of raw milk. MLjekarstvo, 61, 114 -124 .

Plotto, A. (2004). Turmeric: Post-production management, In Turmeric: Post Harvest Operations. Retrieved on Oct 2017 from Food and Agriculture Organization of United Nations (FAO) AGST. Website: www.fao.org.

Poste, L.M., Mackie, D.A., Butler, G. and Larmond, E. (1991). Laboratory methods for sensory analysis of food. Research Branch, Agriculture Canada Publication 1864/E, p. 30-59. Ottawa, Canada: Canadian Communications Group Publishing Centre, Ottawa.

Sandesh, P., Velu, V. and Singh, R.P. (2014). Antioxidant activities of tamarind (Tamarindus indica) seed coat extracts using in vitro and in vivo models. Journal of Food Science and Technology, 9, 1965-1973. https://doi.org/10.1007/s13197-013-1210-9.

Septiana, A.T., Samsi, M. and Mustaufik. (2017). The effect of spices addition and beverage forms on antioxidant activity of Indonesia traditional beverages. Agritech, 37(1), 7-14. https:// doi.org/10.22146/agritech.17001

Setyowati, A. and Suryani, C.L. (2013). The increase of curcuminoids content and antioxidative activity of temulawak and turmeric instant beverages. Agritech, 33(4), 363-370.

SGM. (2006). Basic Practical Microbiology: A Manual. Retrieved on April 2017 from Society for General Microbiology. Website: www.microbiology online.org

Sheikh, T.Z.B., Yong, C.L. and Lian, M.S. (2009). In vitro antioxidant activity of the hexane and methanolic extracts of Sargassum baccularia and Cladophora patentiramea. Journal of Applied Sciences, 13(9), 2490-2493. https://doi.org/10.3923/ jas.2009.2490.2493

Siddiqui, N.A. (2015). Evaluation of thermosensitivity of curcumin and quantification of ferulic acid and vanillin as degradation products by a validated HPTLC method. Pakistan Journal of Pharmaceutical Sciences, 28(1), 299-305.
Siro, I., Kapolna, E., Kapolna, B. and Lugasi, A. (2008). Functional food: Product development, marketing, and consumer acceptance-A review. Appetite, 51, 456-467. https://doi.org/10.1016/j.appet.2008.05.060 